\title{
Reconstruindo a tessitura comum com diálogo, luta e amorosidade
}

\author{
Abdizia Maria Alves de Barros* \\ Maria Dolores Fortes Alves* \\ Vivianne Lins Ebrahim Morcerf
}

\section{Resumo}

Numa homenagem ao centenário de Edgar Morin e Paulo Freire, o presente artigo apresenta uma reflexão sobre suas propostas filosóficas e teórico-metodológicas, e tem como objetivo motivar o leitor a conduzir sua práxis por caminhos de tessituras, diálogos e liberdade, possibilitando olhar a ação pedagógica como um lócus construído por todos, em sua diversidade e singularidade. Para além da comemoração, cabe-nos, sempre, refletir, à luz das contribuições de tais autores, postulados que nos permitam construir novos paradigmas sociais e educacionais que contribuam com a ruptura de ações e posturas desumanas que desconsideram e silenciam o mundo da diversidade humana. Como, a partir de Freire (2019), entendemos que a presença no mundo é a de quem nele se insere, questionamos nosso "lugar" no mundo e toda a nossa condição humana, o que implica em questionar nossa posição no mundo (MORIN, 2000). Nesta perspectiva, a educação surge como um trunfo indispensável à humanidade na construção dos ideais da paz, da liberdade e da justiça social, uma vez que compreendemos que estamos a fazer continuamente o mundo que nos faz, logo, nós e o mundo somos um todo complexo no qual o desenvolvimento da competência humana para a diversidade deve estar

* Doutora em Educação pela PUC/SP. Professora da Universidade Federal de Alagoas. https://orcid.org/0000-0003-3232-9057

** Doutora em Educação pela PUC/SP, Coordenadora e Professora do Programa de Pós-Graduação em Educação da UFAL. E-mail: mdfortes@gmail. com. Orcid: https://orcid.org/0000-0002-2292-8518

*** Mestre em Saúde pelo Centro Universitário CESMAC, Professora do Instituto Federal de Alagoas. Orcid: https://orcid.org/0000-0001-9702-5121 E-mail: vivianne.morcerf@ifal.edu.br 
articulado ao pensar e ao agir, teoria e prática, incluindo ações dialógicas e emancipadoras do mundo e das pessoas diante de seus múltiplos desafios. Palavras-chave: Diálogo, Diversidade, Complexidade, Paulo Freire, Edgar Morin.

\section{Reconstruction of the common fabric with dialogue, struggle and love}

\section{Abstract}

In honor of the centenary of Edgar Morin and Paulo Freire, this article presents a reflection on their philosophical and theoretical-methodological proposals and aims to motivate the reader to conduct their praxis along paths of texture, dialogue and freedom, enabling the look at pedagogical action as locus constructed by all, in its diversity and uniqueness. In addition to the commemoration, it is always up to us to reflect, in light of the contributions of such authors, postulates that allow us to build new social and educational paradigms that contribute to the rupture of inhuman actions and postures that disregard and silence the world of human diversity. As, from Freire (2019), we understand that the presence in the world belongs to those who are part of it, we question our "place" in the world and our entire human condition, which implies questioning our position in the world. (MORIN, 2000). In this perspective, education emerges as an indispensable good for humanity in the construction of ideals of peace, freedom and social justice, as we understand that we are continually making the world that makes us, therefore, we and the world are a whole complex in which the the development of human competence for diversity must be articulated in thought and action, theory and practice, including dialogic and emancipatory actions of the world and people in the face of its multiple challenges.

Keywords: Dialogue, Diversity, Complexity, Paulo Freire, Edgar Morin.

\section{Reconstruir el tejido común con diálogo, lucha y amor}

\section{Resumen}

En un homenaje al centenario de Edgar Morin y Paulo Freire, el presente artículo expone una reflexión acerca de sus propuestas filosóficas y teórico-metodológicas, y se propone animar al lector a conducir su praxis por 
los caminos del tejido, los diálogos y la libertad, permitiendo mirar la acción pedagógica como un locus que se construye entre todos, en su diversidad y singularidad. Más allá la conmemoración, siempre debemos reflejar, a la luz de los aportes de tales autores, postulados que nos permitan la construcción de nuevos paradigmas sociales y educativos que contribuyan a romper las acciones y actitudes inhumanas que desconocen y silencian el mundo de la diversidad humana. Desde Freire (2019) entendemos que la presencia en el mundo es la de quienes se insertan en él, nos cuestionamos nuestro "lugar" en el mundo y toda nuestra condición humana, lo que implica cuestionar nuestra posición en el mundo (MORIN, 2000). Desde esta perspectiva, la educación emerge como un activo indispensable para la humanidad en la construcción de los ideales de paz, libertad y justicia social, ya que entendemos que continuamente estamos haciendo el mundo que nos hace, por lo tanto, nosotros y el mundo somos un todo complejo en el que el desarrollo de la competencia humana para la diversidad debe articularse al pensamiento y a la acción, a la teoría y a la práctica, incluyendo acciones dialógicas y emancipadoras del mundo y de las personas frente a sus múltiples desafíos.

Palabras clave: Diálogo, Diversidad, Complejidad, Paulo Freire, Edgar Morin.

\section{Apontamentos iniciais}

Este artigo é uma homenagem ao centenário de Edgar Morin e Paulo Freire, uma reflexão sobre as propostas filosóficas e teórico-metodológicas desses dois grandes filósofos e educadores. Através destes autores, desejamos motivar o leitor a conduzir sua práxis por caminhos de tessituras, diálogos e liberdade, proporcionando olharmos a ação pedagógica como um lócus construído por todos em sua diversidade e singularidade.

\section{Sobre diversidade}

Quando observamos a dimensão territorial do Brasil, percebemos a sua exuberante riqueza natural e cultural, o que o faz um país de uma diversidade extremamente heterogênea; só em relação ao idioma, segundo o Censo 2010 do Instituto Brasileiro de Geografia e Estatística - IBGE, podemos afirmar que falamos, no 
mínimo, duzentas e setenta e quatro línguas ${ }^{1}$, além dos inúmeros dialetos e sotaques que caracterizam cada espaço, cada lugar de fala, onde se vive e se convive.

Neste sentido, sentimo-nos desafiadas a aprofundar nosso olhar e nossa escuta sobre a diversidade, considerando a atenção sobre a valorização e o respeito necessário às diferenças culturais que se fazem presentes em territórios, diversos e amplos. Tais diferenças podem estar imbricadas aos problemas sociais e à realidade existente, uma vez que realidades e problemas estão sempre permeados por atitudes e ações preconceituosas, segregacionistas, negacionistas, racistas, homofóbicas, que passam a exigir de nós posturas, resistência e lutas contrárias a tais atitudes, sempre em busca de defender e respeitar a diversidade.

Neste sentido, faz-se necessário questionar criticamente as possibilidades da escola enquanto espaço de convivência humana de formação de identidade que possa, um dia, tornar-se um espaço de acolhimento, inclusão, diálogo e respeito à diversidade. Assim, cabe-nos apontar caminhos concretos para a construção de um currículo escolar que seja inclusivo, abalizando as necessidades econômicas, culturais, políticas e histórico-sociais rumo à formação do cidadão e da cidadã numa perspectiva democrática que possibilite exercer o direito constitucional de ampliação dos conhecimentos a partir do contexto no qual se está inserido enquanto sujeito de direito.

Logo, observamo-nos frente aos desafios contemporâneos no que diz respeito à diversidade, principalmente na esfera educacional, nos processos de formação humana. Neste sentido, a escola, lócus privilegiado para a formação do cidadão e da cidadã para a vida coletiva e participativa, faz surgir, no entorno de realidades adversas, pessoas que apontam posturas de vida pautadas em valores éticos, críticos e conscientes do seu papel e protagonismo no contexto socioemocional, histórico, político e cultural.

Segundo o IBGE, os resultados do Censo 2010 apontam para 274 línguas indígenas faladas por indivíduos pertencentes a 305 etnias diferentes. 
Assim, faz-se necessário refletir o papel da educação nesse processo de construção humana, como possibilidade de se tecer redes e caminhos possíveis para a construção de saberes e novos conhecimentos. Principalmente, no atual contexto pandêmico em que estamos convivendo enquanto vítimas do Sars-CoV-2; vivenciando inúmeros momentos de incertezas, de escancaramento das desigualdades sociais, e de percepção das "invisibilidades" humanas e suas diversidades. Tudo isso vem a exigir um novo olhar, novos diálogos e novas posturas diante das inovações científicas, tecnológicas, e desta nova consciência do outro; desenvolvendo novas formas de pensar, agir, tomar decisões, na perspectiva de se resgatar os valores essenciais que venham a contribuir para a humanização de todas as pessoas.

Destarte, buscamos, para além da comemoração do centenário desses dois grandes filósofos e educadores, Edgar Morin e Paulo Freire, refletir, à luz de suas contribuições teórico-filosóficas, postulados que nos permitam construir novos paradigmas sociais e educacionais que contribuam para a ruptura de ações e posturas desumanas que desconsideram e silenciam o mundo da diversidade humana.

Observamos, ao longo da caminhada de estudos, as aproximações das concepções filosóficas de Paulo Freire e Edgar Morin no sentido de contribuírem para a superação das posturas de desumanização e desrespeito à diversidade. Freire (2018, p. 114) nos traz a concepção de esperança em um mundo livre, justo, considerando a desalienação e a humanização dos sujeitos como possibilidade de resgatar a sua liberdade enquanto um movimento de luta e de resistência, quando nos afirma que

[...] a desumanização que resulta da "ordem" injusta não deveria ser uma razão da perda da esperança, mas, ao contrário, uma razão de desejar ainda mais, e de procurar sem descanso, restaurar a humanidade esmagada pela injustiça. Não é, porém, a esperança um cruzar de braços e esperar. Movo-me na esperança enquanto luto e, se luto com esperança, espero. 
Nesse contexto, o autor nos indica a educação como caminho para a construção da consciência crítica das pessoas, como ação político-pedagógica de fortalecimento da consciência de cidadania e de pessoa de direito à vida dentro de sua diversidade e pluralidade, observando o movimento e as mudanças próprias do viver em sociedade e rompendo com o saber vertical imposto pela classe dominante. Deste modo, opõe-se ao autoritarismo e cria possibilidades de vida e de educação que consideram a complexidade do saber das classes trabalhadoras como um saber transformador das condições de subalternidade e silenciamento, rumo a uma condição de respeito e de visibilidade ao diferente, às diversidades.

Nesse ponto, encontramos as proximidades entre Freire (1992; 2000) e Morin (1995) quando nos apresentam uma concepção de educação como um processo diverso, interativo, envolvendo aspectos sociais, culturais, políticos e psicológicos observados nos mais distintos campos da ação humana.

Morin (1995) nos apresenta a educação como um projeto em permanente construção na perspectiva da valorização dos processos de ensinar e aprender promovendo a capacidade de autoformação humana, mostrando-nos, à luz do seu paradigma da complexidade, possibilidades de ruptura com modelos pré-estabelecidos, considerando ser possível a "liberdade" humana e situando a inteligência complexa como possibilidade do surgimento de novas oportunidades em um novo tempo.

Nesse sentido, vamos percebendo que a educação como Prática da Liberdade assumida por Freire (2000) tem como categoria central o diálogo como princípio básico para a emancipação humana, assim como o respeito à diversidade, dado que só através do diálogo se pode estabelecer, de fato, o respeito a toda diversidade humana.

Considerando os aspectos apontados, ancoramo-nos no princípio da complexidade defendido nas obras de Edgar Morin para defender uma educação que supere a visão dual do conhecimento, para tal, necessário se faz pensar em uma educação multidi- 
mensional, dialógica, aberta ao novo e com capacidade de articular saberes historicamente tratados de forma fragmentada.

Esta é a nossa perspectiva de superarmos as divisões, a fragmentação e os silenciamentos diante da diversidade e da pluralidade cultural na sociedade, sempre na perspectiva do diálogo, do respeito humano, da complexidade e da liberdade; aspectos estes, defendidos tanto por Freire (1992; 2000) quanto por Morin (1995).

\section{Sobre diálogo}

Ao conhecer Edgar Morin já conhecendo os escritos de Paulo Freire, e vice-versa, dificilmente não nos perguntamos quem é discípulo de quem. Sobre o diálogo, para exemplificar, ambos o afirmam enquanto saída rumo a uma educação democrática e cidadã. Para Freire (2019, p. 39), "Não há inteligibilidade que não seja comunicação e intercomunicação e que não se funde na dialogicidade", incluindo o "pensar certo" como dialógico e, portanto, não polêmico. Morin (2017, p. 56), por sua vez, ao tratar da indestrutibilidade das incertezas, adianta-nos que a primeira revolução científica do século XX subverteu a ordem do mundo ao "substituí-la por uma relação de diálogo (ao mesmo tempo complementar e antagônica) entre ordem e desordem."

A existência, porque humana, não pode ser muda, silenciosa, nem tampouco pode nutrir-se de falsas palavras, mas de palavras verdadeiras, com que os homens transformam o mundo. Existir, humanamente, é pronunciar o mundo, é modificá-lo. O mundo pronunciado, por sua vez, se volta problematizado aos sujeitos pronunciantes, a exigir deles novo pronunciar.

Não é no silêncio que os homens se fazem, mas na palavra, no trabalho, na ação-reflexão.

$[\ldots]$

Por isto, o diálogo é uma exigência existencial. E, se ele é o encontro em que se solidariza o refletir e o agir de seus sujeitos endereçados ao mundo a ser transformado e humanizado, não pode reduzir-se a um ato de depositar idéias de um sujeito no outro, nem tampouco tornar-se simples troca de idéias a serem consumidas pelos permutantes. (FREIRE, 2018, p. 108 e 109) 
Assim, a necessária e urgente reforma do pensamento acaba por prescindir e ao mesmo tempo fomentar uma episteme voltada ao contexto e ao complexo que nos cerca e nos faz no mundo e junto com o mundo, ligando e enfrentando incertezas, e substituindo toda e qualquer "causalidade linear e unidirecional por uma causalidade em círculo e multirreferencial", corrigindo, desta forma, a engessada lógica clássica através dialogicidade, esta sim, capaz de engendrar ideias concomitantemente complementares e antagônicas. (MORIN, 2017, p. 92)

Na mesma linha de raciocínio, Paulo Freire é bastante contundente ao afirmar que se abrir ao mundo e ao outro introduz a relação dialógica a partir da compreensão da inconclusão do ser que se expande e se reconhece enquanto inconcluso diante do constante movimento histórico (FREIRE, 2019). O que se coaduna ao pensamento de Miguel Arroyo (2014, p. 28) ao pensar sobre a pedagogia e afirmar que os coletivos sociais, em constante movimento, anunciam que as teorias pedagógicas são dinâmicas e fazem parte dos processos sociais e históricos de "humanização/emancipação" e de "reação à desumanização/subordinação".

Logo, concordamos com os três teóricos, pois, em suas vastas bibliografias, eles se põem a lançar mão do diálogo como fio de tessitura para uma cidadania humana e planetária, cabendo ao educador construir sua práxis pedagógica com e pelo diálogo que une - num movimento dialógico - ternura, coragem, sabedoria, esperança e ação.

\section{Sobre práxis pedagógicas}

Diante da temática da educação, em várias de suas obras Paulo Freire nos apresenta a neutralidade como uma impossibilidade, e nos alerta quanto à constante insistência das ideologias dominantes em insinuar tal neutralidade, segue um dos trechos: "Que é mesmo a minha neutralidade senão a maneira cômoda, talvez, mas hipócrita, de esconder minha opção ou meu medo de acusar a injustiça? "Lavar as mãos" em face da opressão é reforçar o poder do opressor, é optar por ele.” (FREIRE, 2019, p. 109). 
Diante do questionamento citado, faz-se necessário compreender a problemática dos currículos a serem instituídos, dado representarem sempre uma seleção organizada dos conteúdos a aprender, os quais, por sua vez, regulam a prática didática que se desenvolverá durante a escolaridade, atuando como reguladores dos conteúdos ao passo que abrangem a função organizadora e unificadora do ensinar e do aprender, sem esquecer que neles próprios se reforçam as fronteiras que delimitam seus componentes. (SACRISTÁN, 2013, p. 17)

Apesar dessa primeira e aligeirada compreensão conceitual do que vem a ser o termo currículo, entendemos que se une a tal entendimento o pensamento de Arroyo (2014) ao afirmar que, como estamos diante de educandos diferentes feitos desiguais pelas circunstâncias que os cercam, como tais indivíduos carregam consigo suas diferenças/desigualdades para o ambiente escolar, seria ingênuo pensá-los como entes genéricos. Para o autor, o pensamento hegemônico que entende o diferente como subalterno, inferior, é o mesmo pensamento hegemônico utilizado como instrumento de legitimação de relações sociopolítico econômicas de dominação/ subordinação; ao passo que, eximir-se de pensar acerca do currículo só reforça e perpetua o padrão de poder/saber dominante.

Ao mesmo tempo, ocultar ou negar a centralidade dos diferentes contextos humanos existentes na engrenagem da nossa história é empobrecê-la e empobrecer o pensamento e as políticas e diretrizes educacionais - empobrecendo-se, assim, o próprio currículo - dado que o primeiro direito ao conhecimento é o direito a saber-se. (ARROYO, 2014). Apesar de tal conhecimento já se fazer presente nos ambientes educacionais, infelizmente, raros são os momentos que paramos, de fato, para refletir sobre a conjuntura sociopolítico econômica mundial e pensar nossos currículos.

Ultimamente, resta-nos mais certezas quanto à magnitude do problema que supomos estar enfrentando e, por estar a conhecer de onde emerge tamanha dimensão, tão dinâmica e poderosa, enxergamo-nos ainda mais pessimistas quanto ao nosso presente 
e futuro como educadoras; pois compreendemos currículo como identidade e tal identidade como relacional, portanto, marcada pela diferença e interseccionada pelas relações sociais, culturais, políticas e econômicas de dominação e subordinação dos indivíduos enquanto indivíduos e coletivos humanos.

Assim, a presença dos filhos desses coletivos diferentes feitos desiguais representa um fato histórico-político que precisa ser encarado como tal, uma vez que lembram ao sistema escolar que tais diferenças e/ou desigualdades não podem ser simplificadas, mas encaradas como uma realidade nacional produto dos brutais e abissais processos de segregação, inferiorização e invisibilização de determinados grupos sociais, estes, também entendidos como minorias e vistos constantemente enquanto problema. (ARROYO, 2014)

Para Morin, mesmo tomando-se em conta apenas o ponto de vista biológico,

o indivíduo é o produto de um ciclo de reprodução; mas este produto é, ele próprio, reprodutor em seu ciclo, já que é o indivíduo que, ao se acasalar com indivíduo de outro sexo, produz esse ciclo. Somos, portanto, produtos e produtores ao mesmo tempo. Assim também, quando se considera o fenômeno social, são as interações entre indivíduos que produzem a sociedade; mas a sociedade, com sua cultura, suas normas, retroage sobre os indivíduos humanos e os produz enquanto indivíduos sociais dotados de uma cultura. (MORIN, 2017, p. 119)

Desse modo, podemos compreender que temos agora uma ideia suficientemente complexa da autonomia e do indivíduo enquanto ente do e no mundo; mas faltando-nos ainda a compreensão do sujeito, que seria alcançada a partir da compreensão de que as dimensões cognitivas ou biológicas são interdependentes, uma servindo de base para a outra, de maneira recíproca; estando os genes a constituir "um patrimônio hereditário de natureza cognitiva/informacional da célula", ao passo que, todo e qualquer ser vivo, com ou sem sistema neurocerebral, "retira informações de seu meio ambiente e exerce uma atividade cognitiva inseparável de sua 
prática de ser vivo", o que desemboca na conclusão de que a "dimensão cognitiva é indispensável à vida.” (MORIN, 2017, p. 119)

No entanto, particularmente, notamos as escolas cada vez menos comprometidas com objetivos voltados à emancipação do ser humano, e cada vez mais subjugada às normas e interesses capitais que hoje estão diretamente relacionados ao capital financeiro internacional. E, seja em que nível de atuação for, mesmo diante das urgentes e necessárias reflexões educacionais acerca dos contextos no qual vivemos e do qual fazemos parte, estamos sempre às voltas com uma formação para o mercado, para o empreendedorismo e para a alienação. E, se continuarmos a não compreender de que lugar viemos, de que lugar falamos, não iremos conseguir compreender o mundo que nos cerca e seremos incapazes de propor mudanças ao nosso já tão hostil conviver.

Nas palavras de Izabel Petraglia (2011, p. 77), os ensinamentos de Edgar Morin apontam para a superação da "policrise" e da "agonia planetária" na qual se encontra inserida a humanidade, o que a faz recomendar "a solidariedade, advinda da tomada de consciência, como fator de compreensão para os seres humanos acerca de seus destinos no planeta", gerando, portanto, a necessidade de pensar o contexto educacional a partir da complexidade, e fincando-se na ideia da auto-eco-organização desenvolvida pelos indivíduos em sua interação com o meio.

Para a autora, "o currículo escolar é mínimo e fragmentado", sendo insuficiente, na maioria das vezes, qualitativa e quantitativamente, não favorecendo a dialogicidade entre os saberes e a "visão do todo, do curso e do conhecimento uno". (PETRAGLIA, 2011, p. 79). Desta maneira, sem a perspectiva do todo, segue o processo ensino-aprendizagem sem cumprir seu papel emancipador e cidadão perante os entes que o fazem, e fica o questionamento: se os processos cognitivos são dinâmicos, por que o processo ensino-aprendizagem ou o currículo continuam estáticos?

$\mathrm{Na}$ mesma linha de raciocínio, Frei Betto (2018, p. 94) é categórico ao afirmar que "Uma educação crítica e participativa é capaz 
de reproduzir as bases materiais e espirituais de uma sociedade alicerçada na solidariedade". Desse modo, é a educação que tem o poder de fazer sucumbir uma determinada racionalidade hegemônica diante duma outra, mas, para que isso aconteça, é imprescindível que a nova episteme não seja simplesmente teórica, mas esteja imbricada e comprometida com os "processos efetivos de produção material da existência”. Logo, fazer-se existir é pôr-se, imbricar-se na práxis da ação-reflexão-ação. É constituir-se na autoria de si mesmo como legítimo e único.

\section{Reconstruindo a tessitura comum com diálogo, luta e amorosidade}

E, como um fio de Ariadne, Edgar Morin e Paulo Freire apresentam-nos o convite à religação, à tessitura, como caminhos de amorosidade, diálogo, sensibilidade, ternura. O reencontro daquilo que significa viver, conviver: conviver é tecer, encontrar o caminho. Religar é reencontrar o caminho, é mostrar que há um fio que nos liga, que nos une, que nos mostra o sentido.

Ação-reflexão-ação, caminhos para libertação. Vemos em Freire (2018) que a ação está relacionada à práxis transformadora que se faz autêntica na união da ação e da reflexão. Converge e conversa com Edgar Morin (2000) quando nos traz que toda ação escapa à vontade de ser do seu realizador. Consequentemente, caímos na retroação e, assim sendo, devemos atuar com responsabilidade sobre nossa ação, porquanto toda ação retroage a quem a praticou, fugindo do controle, pois entra na ecologização.

A partir de Freire (2019), percebemos que a autonomia se construiu lentamente e com muita luta. Igualmente, a liberdade encontra seu "lugar" antes "ocupado" pela dependência e opressão. Assim, tanto em Freire (2018; 2019) quanto em Morin (2000; 2003) a autonomia e a Co dependência constituem-se como espaços de liberdade, luta social, humana e planetária, por todos os cantos da Terra. Contudo, percebemos que, todo sistema, para manter sua autonomia, necessita da abertura ao ecossistema do qual se nutre 
e ao qual se transforma e nos transforma, fazendo-nos transgredir para novas vias.

Freire (2018) nos chama para a consciência e superação da realidade a fim de que construamos uma consciência crítica apropriando-nos de nossos posicionamentos epistemológicos. Logo, Morin (2000) nos invoca a consciência de que habitamos todos - seres de todas as espécies - a biosfera terrestre, o que nos conduz ao abandono do sonho prometeico do domínio do universo e nos move a nutrir a aspiração de convivermos pacificamente sobre a Terra.

A Curiosidade epistemológica apresentada tanto por Paulo Freire (2019); quanto por Edgar Morin (2000) nos vem como um estímulo à capacidade de se arriscar, de aventurarmo-nos. Logo, como uma força criadora, potência do aprender, tal curiosidade produtora de saberes é nutrida pelo livre exercício da criatividade. As faculdades de criatividade e curiosidade, aspectos da curiosidade epistemológica, são mais vivas durante a infância e a adolescência, contudo, com frequência, a instrução as elimina ao invés de estimulá-las. Quiçá, caso estejam adormecidas, a educação pudesse fazê-las despertar.

Quanto à dialogicidade, dizemos da nossa potencialidade de tecer conversações sem o desejo de aniquilar a ideia do outro. Logo, dizemos que há inteligibilidade na comunicação e na intercomunicação que se funde na dialogicidade. Desta feita, tanto Freire (2019) quanto Morin (2003) nos convocam a pensar certo enquanto modo de conversação dialógico e não polêmico. Para Morin (2003), o princípio dialógico pode ser definido como a associação complexa de instâncias imprescindíveis, conjuntamente necessárias à existência, ao funcionamento e ao desenvolvimento de um fenômeno organizado.

A Ética do humano como uma antropoética deveria ser para nós como um dos princípios norteadores de justiça, esperança, sinceridade, moralidade, honestidade e luta. Corrobora conosco tanto Freire (2019) quanto Morin (2000) nos mostrando que a ética é do humano enquanto antropoética, portanto, devem consistir e coexistir trinariamente: indivíduo, sociedade e espécie. Desta trilogia, emerge a consciência de nosso espírito propriamente humano. 
Para Freire (2018), a humanização se traduz em assumir responsavelmente a missão de homem, portanto, tal ser há de aprender a dizer a sua palavra, porquanto, com ela, constitui-se. Nisso, a comunhão humana que integra o próprio homem é que instaura o mundo em que se humaniza. Homem e mundo humanizam-se. $\mathrm{O}$ movimento de compreensão antes da condenação se faz como o caminho da humanização (MORIN, 2002).

Conforme Freire (2018) e Morin (2003), somos todos seres incompletos e inacabados, e, igualmente, é a realidade a qual pertencemos e construímos dia após dia. Logo, para Morin, a complexidade percebe o humano enquanto ser epistêmico, como um ser não dividido, e sim, conectado, inter-relacionado. Isso nutre nossa tensão permanente entre o reconhecimento do inacabado e da incompletude, bem como, a consciência de que o conhecimento é aspiração que o saber não é parcelado, não é dividido, não é reducionista, e sim, constitui-se em/na tessitura.

Já no campo da política, da polis, da politização, Freire (2018) e Morin (2000) nos desafiam à conscientização. Politizar, polinizar é fazer emergir a consciência da tessitura de que nossas ações estão co-imbricadas, interligadas. Todo e parte enquanto cultura, luta, trabalho, afetam-se. Destarte, cultura popular é política popular. Pessoas fazem o mundo, a cultura que, recursiva e retroativamente as fazem. Polis e povo politicamente coexistem, retroalimentam e se reconstroem. Global e local estão interconectados, pensamento e ação são conectados e nos conectam ao duplo par "local e globalmente" em uma tessitura complexa (MORIN, 2003).

Destarte, construir nosso "lugar" no mundo, percebendo-nos enquanto sujeitos singulares e múltiplos imbricados com o mundo, indivíduo e espécie, ser social, espiritual, cognitivo e emocional, põe-nos numa posição em face do mundo que é de quem a ele pertence. Dizemos isso, porque nossa presença no mundo é a de quem nele se insere (FREIRE, 2018). Assim, quando questionamos nosso "lugar" no mundo, questionamos também toda a nossa condição humana e, questionar nossa condição humana implica em 
questionar nossa posição no mundo (MORIN, 2000). Eu faço o mundo que me faz, logo, eu e o mundo somos um todo complexo.

O desenvolvimento da competência humana para a diversidade deve ser articulado ao pensar e ao agir, entre teoria e prática. Também deve incluir ações dialógicas e emancipadoras do mundo e das pessoas, posto que, "face aos múltiplos desafios do futuro, a educação surge como um trunfo indispensável à humanidade na construção dos ideais da paz, da liberdade e da justiça social." (DELORS, 2000, p. 19). Assim, todo processo de mudança, como aprimoramento da condição humana, liberdade de expressão e comunicação, é de vital importância para todos nós e de importância ímpar para todo educador.

Concordamos com Alves (2009) quando nos lembramos que todo processo educativo deve seguir conectado com as atuais exigências presentes na complexidade social, econômica, política, cultural e espiritual. É nesse contexto que as subjetividades e as intersubjetividades se nutrem dentro das relações dialógicas. Assim, todo caminho do ser humano deve considerá-lo enquanto diverso e em sua inteireza. Para que isso ocorra, o nosso conviver em quaisquer espaços políticos e relacionais, deve se aparar no diálogo, na escuta sensível, que nos conduz ao autoconhecimento e que nos remete ao entrelaçamento na tessitura comum: a complexidade. Sigamos...

O diálogo dialógico é uma ferramenta que nos liberta. É no diálogo que cada sujeito pode dizer sua palavra, ouvir a palavra do outro e juntos construírem palavras integradoras. (BOHM, 2005; ALVES, 2013; 2016). Assim, é no diálogo atento ao olhar-escuta, sensível a tudo que nos cerca e que está dentro de nós, (BOHM, id) que percebemos que quanto mais sabemos de nós mesmos, mais sabemos do outro. O outro é meu espelho e diz muito sobre mim. Igualmente, todo conhecimento se transforma em autoconhecimento e todo autoconhecimento se transforma em conhecimento, como nos ensina Boaventura de Souza Santos (1996).

Logo, tudo está tecido em conjunto e desta tessitura comum faz parte o sujeito triúnico, pois em cada ser humano que existe há um 
indivíduo-indiviso inserido e em constante interação com a sociedade e a natureza. Devemos cuidar do equilíbrio desse Triângulo da Vida (D’AMBRÓSIO, 1997).

\section{Conclusão inconclusa}

A perspectiva de reconstruir a tessitura comum com diálogo, luta e amorosidade se faz possível pelo ato de educar para as incertezas (MORIN, 2006). Portanto, a diversidade nos mostra que tudo é incerto, tudo muda e tudo se transforma. Toda verdade é sempre mutável, e a verdade "semente" é somente válida para um determinado momento fugaz e num determinado contexto. Todo ponto de vista depende da perspectiva do nosso olhar, afinal, toda realidade é multissensorial e multidimensional. (NICOLESCU, 2011).

Concordamos com a afirmação de Alves (2016) quando expressa que, como seres multidimensionais que compartilham energias, sentimentos e sabedorias em diversos níveis de realidade - macrofísico e microfísico -, somos mais que matéria, somos corpo-mente-espírito: organismo, cognição, afetividade, espiritualidade, intuição e emoção que se materializa através da interação política, social e cultural. O caminho do conhecimento perpassa o caminho, interdependência, da abertura da humildade do saber construído, tecido junto com o outro e com o todo. Assim, dizemos que viver deveria ser um ato poético e político de construir a polis, a sociedade em sua diversidade com diálogo, abertura, ternura, generosidade, amorosidade, responsabilidade ética, esperança, luta e liberdade. Salve, Salve Edgar Morin e Paulo Freire.

\section{Referências}

ALVES, M. D. F. Construindo Cenários e Estratégias de Aprendizagem Integradoras (inclusivas). 276pp.Tese [Doutorado] - Programa de Pós-Graduação em Educação: Currículo, Pontifícia Universidade Católica de São Paulo. São Paulo, 2013.

ALVES, M. D. F. Favorecendo a inclusão pelos caminhos do coração: complexidade, pensamento eco-sistêmico e transdisciplinaridade. Rio de Janeiro, WAK, 2009. 
ALVES, M. D. F. Práticas de aprendizagem integradoras e inclusivas: autoconhecimento e motivação. Rio de Janeiro: WAK, 2016.

ARROYO, M. G. Outros sujeitos, outras pedagogias. $2^{\text {a }}$ ed. Petrópolis, RJ: Vozes, 2014.

BOHM, D. Diálogo: comunicação e redes de convivência. São Paulo: Palas Athena, 2005.

D’AMBRÓSIO, U. Transdisciplinaridade. São Paulo: Palas Athena, 1997.

DELORS, J. Educação, um tesouro a descobrir. São Paulo: Cortez, 2000.

FREIRE, P. Educação como prática da liberdade. 23. ed. Rio de Janeiro, Paz e Terra, 2000.

FREIRE, P. Pedagogia da autonomia: saberes necessários à prática educativa. $59^{a}$ ed. Rio de Janeiro/São Paulo. Paz e Terra, 2019.

FREIRE, P. Pedagogia da esperança. Rio de Janeiro, Paz e Terra, 1992.

FREIRE, P. Pedagogia do oprimido. $66^{\mathrm{a}}$ ed. Rio de Janeiro/São Paulo. Paz e Terra, 2018.

IBGE. Indígenas. Estudos especiais. O Brasil indígena. Disponível em: https:// indigenas.ibge.gov.br/estudos-especiais-3/o-brasil-indigena/lingua-falada. Acesso em: 04 ago 2021.

MORIN, E. Os sete saberes necessários à educação do futuro. São Paulo, Cortez, 2000.

MORIN, E. O método: V. A humanidade da humanidade. A identidade humana. Porto Alegre: Sulina, 2002.

MORIN, E. A cabeça bem-feita: repensar a reforma, reformar o pensamento. Tradução Eloá Jacobina. 23ª edição - Rio de Janeiro: Bertrand Brasil, 2017.

NICOLESCU, B. Reforma da educação e do pensamento: Complexidade e transdisciplinaridade, (2004). Disponível em: http:/ /www.engenheiro2001.org.br/ curriculos.htm. Acesso em: 06 mar 2021.

PETRAGLIA, I. Edgar Morin: a educação e a complexidade do ser e do saber. $13^{\mathrm{a}}$ ed. Petrópolis, RJ: Vozes, 2011.

SACRISTÁN, J. G. Saberes e incertezas sobre o currículo. Penso Editora, 2013. 